\title{
EXPECTATIVAS DE DOCENTES SOBRE O ENSINO DO CUIDADO EM SAÚDE MENTAL*
}

TEACHER'S EXPECTATIONS ABOUT THE TEACHING OF CARE IN MENTAL HEALTH*

EXPECTATIVAS DE DOCENTES SOBRE LA ENSEÑANZA DEL CUIDADO EN SALUD MENTAL*

\section{Luciane Prado Kantorski ${ }^{1}$, Leandro Barbosa de Pinho ${ }^{2}$, Toyoko Saeki ${ }^{3}$, Maria Conceição Bernardo de Mello e Souza ${ }^{3}$}

RESUMO - Objetivo: O presente estudo tem por objetivo analisar as expectativas de docentes de enfermagem psiquiátrica sobre o ensino do cuidado em saúde mental. Metodologia: A abordagem metodológica é qualitativa e descritiva-analítica, na qual foram utilizados como instrumento para a coleta de dados a entrevista semi-estruturada e em profundidade aplicada a 03 (três) docentes, em 2001. Resultados: Observamos nos resultados que os docentes enfatizam a necessidade da humanização do atendimento em saúde mental, centrado em um paradigma da reforma psiquiátrica. Conclusão: Concluímos que o contexto de ensino-aprendizagem de saúde mental tem sofrido influência de abordagens como a psicanálise, a saúde coletiva e o relacionamento interpessoal.

PALAVRAS CHAVE: Saúde mental; Ensino; Enfermagem.

ABSTRACT - Objective: The present study has for objective to detach the expectations of professors of psychiatric nursing on the education of the care in mental health. Methodology: The methodological boarding is qualitative and descriptive-analytical, in which the half-structuralized interviews had been used as instruments for the collection of data applied the 03 (three) professors, in 2001. Results: It was observed in the results that the professors emphasize the necessity of the humanization of the attendance in mental health, centered in a paradigm of the psychiatric reform. Conclusion: We concluded that the context of teaching-learning of mental health has been suffering influence of approaches as the psychoanalysis, the collective health and the relationship interpessoal.

KEY WORDS: Mental health; Teaching; Nursing.

RESUMEN - Objetivo: Este estudio objetiva destacar expectativas de los docentes de enfermería psiquiátrica sobre la enseñanza del cuidado en salud mental. Metodología: El abordaje metodológica utilizada fue la cualitativa y descriptiva-analítica, por la que se ha utilizado como instrumentos de coleta de datos entrevistas parcialmente estructuradas aplicadas a tres docentes, en 2001. Resultados: Se ha observado en los resultados que los docentes enfatizan la necesidad de la humanización de la atención en salud mental, centrado en un paradigma de la reforma psiquiátrica. Conclusión: Concluimos que el contexto de enseñanza-aprender de salud mental ha sido influenciada de abordajes como el psicoanálisis, la salud colectiva y las relaciones interpersonales.

PALABRAS CLAVE: Salud mental; Enseñanza; Enfermería.
* Relato da pesquisa intitulada "Concepções teóricas e instrumental utilizado no ensino da enfermagem psiquiátrica e saúde mental em um contexto de reformulação da assistência psiquiátrica nas últimas décadas", financiada pelo CNPq.

Docente da Faculdade de Enfermagem e Obstetrícia da Universidade Federal de Pelotas / RS. Doutora em Enfermagem. Pelotas - RS. E-mail: kantorski@uol.com.br. Apoio CNPq.

2 Enfermeiro. Mestre em Enfermagem pela UFSC. Doutorando em Enfermagem Psiquiátrica pela Escola de Enfermagem de Ribeirão Preto - USP. E-mail: Ibpinho@uol.com.br. Apoio CNPq.

3 Docente do Departamento de Enfermagem Psiquiátrica e Ciências Humanas da Escola de Enfermagem de Ribeirão Preto da Universidade de São Paulo - USP. Doutora em Enfermagem. Email: maryto@eerp.usp.br 


\section{INTRODUÇÃO}

O ato de cuidar é um processo que compreende uma série de conceitos, práticas e visões de mundo em que estão envolvidas as nossas atitudes, o modo de como olhamos e tratamos alguém, nossa disposição pessoal para interagir com o outro, o respeito para com ele. Cuidar é uma atividade complexa, que se identifica, da mesma forma, com nossa natureza complexa (ARRUDA, 2003).

Entendemos que as diferentes formas de se entender o cuidado interfere na vida prática da profissão de enfermagem. O cuidado é nossa maior responsabilidade para/com o outro, principalmente nos momentos de sofrimento. Entretanto, é no estado de sofrimento em que se evidenciam as diferentes dificuldades/possibilidades de se promover o cuidado, entre elas os instrumentos necessários tanto para o preparo pessoal como para o preparo profissional do enfermeiro. Faz parte da disciplina de enfermagem psiquiátrica trabalhar com esse contexto de cuidado permeado por relações interpessoais.

As diferentes possibilidades de se promover o cuidado em enfermagem psiquiátrica vêm junto ao processo de constituição da disciplina de enfermagem psiquiátrica no Brasil. A década de 50 foi marcada pela inserção do ensino de enfermagem psiquiátrica nos currículos dos cursos de graduação em enfermagem despontando a psicanálise como uma alternativa de estudar/compreender os comportamentos humanos. Mais tarde, na década de 70 , surge o relacionamento terapêutico, que, com sua eficácia na promoção de saúde mental, configurou-se como modelo teórico da maioria das disciplinas de enfermagem psiquiátrica no país. Conteúdos como a relação interpessoal e a comunicação mantêm-se nos currículos até a atualidade e contribuem para orientar a prática da enfermagem psiquiátrica e saúde mental em diferentes espaços de cuidado e aprendizagem. Noções oriundas do preventivismo de Caplan como as de saúde mental, as de crises acidentais e do desenvolvimento são explicitadas nos currículos da década de 70 até os dias de hoje. Já na década de 80 , iniciam as discussões sobre a reforma psiquiátrica, assim como a preocupação constante de alguns enfermeiros na melhoria das condições de atendimento ao portador de sofrimento psíquico (SOUZA e ALENCASTRE, 1999).

O cuidado em saúde mental tem sua tônica no relacionamento afetivo-emocional com alguém que se encontra, na maioria das vezes, longe de uma comunicação efetiva com o outro, situado em uma realidade só sua difícil de ser manejada, entendida e interpretada. $\mathrm{O}$ relacionamento interpessoal estabelecido consiste em um pré-requisito, que é a dedicação de ambas as partes (profissional e paciente), sendo um desafio permanente para os envolvidos na experiência. É inteligível, portanto, que nesse relacionamento transpareçam as nossas deficiências, limitações e os nossos conflitos, que podem ser resgatados na discussão teórica da disciplina de enfermagem psiquiátrica na academia.

Diante dessa realidade, este estudo tem como objetivo identificar expectativas de docentes da disciplina de enfermagem psiquiátrica sobre 0 ensino diante das tendências de cuidado em saúde mental.

\section{METODOLOGIA}

Neste estudo, realizamos uma pesquisa qualitativa e descritivo-analítica. Foi utilizada, como instrumento de pesquisa, a entrevista semiestruturada, realizada com três docentes de enfermagem psiquiátrica e saúde mental selecionados entre nove escolas de enfermagem públicas do Estado de São Paulo. O critério de seleção adotado foi a identificação de docentes de Escolas Públicas do Estado que, em meados de 2001, incorporaram aulas práticas de enfermagem psiquiátrica em serviços substitutivos ao hospital psiquiátrico, como Núcleos ou Centros de Atenção Psicossocial (NAPS/CAPS), Hospital-Dia e Ambulatórios de Saúde Mental articulados com a Estratégia da Saúde da Família. Foi realizada uma entrevista em profundidade com os docentes selecionados, em seus locais de trabalho, que teve duração média de 1 hora e meia e foram gravadas.

$\mathrm{O}$ projeto de pesquisa foi submetido à apreciação e aprovado pelo Comitê de Ética da Escola de Enfermagem de Ribeirão Preto-USP, sendo seguidos os procedimentos éticos previstos pela legislação vigente, como obtenção da concordância das instituições estudadas e assinatura do termo de consentimento livre e informado pelos sujeitos da pesquisa.

A entrevista cujos resultados são apresentados neste artigo enfocou as expectativas dos docentes em relação ao ensino na área específica Os docentes foram classificados segundo a ordem estipulada pelos pesquisadores na coleta das entrevistas, recebendo a letra "D" seguida do número correspondente. Ex.: D1 - Corresponde ao primeiro docente entrevistado.

Com relação à análise dos dados das entrevistas, procedemos à análise temática das entrevistas. A análise dos dados ocorreu a partir das seguintes etapas: ordenação, classificação e análise final (MINAYO, 1998). Após re-leitura incessante de todo o material a fim de que pudéssemos encontrar as convergências/divergências nas falas dos docentes procedemos à discussão dos mesmos, a partir de um eixo temático. O principal tema emergido dos dados consiste na humanização do cuidado em saúde mental, que passaremos a discutir a seguir.

\section{RESULTADOS}


Entender a trajetória do louco e re-significá-la faz parte dum conjunto de estratégias que visam à humanização do atendimento em saúde mental, manifestada como expectativa dos docentes entrevistados em relação ao processo de ensinoaprendizagem:

"Perceber que atrás daquele louco que eu tanto temo tem uma pessoa, acho que isso é bastante significativo... perceber que aquela pessoa tem desejos, que aquela pessoa diz coisas que são pertinentes, que aquela pessoa pode sustentar uma posição que é pertinente por mais que me pareça absurda... Acredito que todo paciente pode responder. Nem que leve dez anos, mas um dia, alguma coisa vai aparecer por ali. A gente tem que apostar no vínculo (...) Quando eles [alunos] percebem que a intervenção deles tem um peso, pois dizer uma bobagem para alguém faz diferença e isso pode fazer com que a pessoa piore ou melhore, eu acho extremamente gratificante" (D1).

"Eu acho que a principal questão é de valorizar a possibilidade da pessoa em sofrimento psíquico poder viver na comunidade, na sociedade de uma forma normal, tranqüila como qualquer outra pessoa e que ele tenha direito de receber a atenção que ele precisa para o seu problema de saúde como qualquer outra... Minha expectativa é de que a gente possa mostrar para o aluno que a área de enfermagem, a área da psiquiatria, ela não difere das outras áreas. Na verdade eu acho que o aluno vem com conceitos, como os da população de uma forma geral. Ou seja, de que o doente mental não tem condição de fazer nada, que ele é agressivo, que pode atacar uma pessoa num momento qualquer, até matar. Enfim, de que ele tem que ser marginalizado pela sociedade" (D2).

"Dar liberdade pro aluno trazer as dificuldades pra gente e quando o aluno percebe que a gente vai abordar um paciente, conversar... Acho que ele tem que participar até ativamente da coisa... Hoje eu me sinto assim, até de certa forma, bem à vontade pra ensinar porque todo aquele trabalho, o trabalho em equipe... Eu comecei a viver isso" (D2).

"Minha expectativa é que a gente possa mostrar para o aluno que o portador de transtorno mental não é um fantasma. Não é um bicho de sete cabeças, não é um E.T., ou coisa do tipo. São pessoas como qualquer outra pessoa que tem uma doença, um transtorno que precisa ser cuidado... A estratégia que eu uso, eu sempre procuro estar junto, conversar com o paciente, abordar o paciente nas diversas situações, nos diversos comportamentos que ele possa apresentar e que o aluno tenha facilidade para observar. Tento trabalhar muito com os alunos as minhas expectativas com eles $e$ (...) Que eles tenham claro que pessoas em sofrimento psíquico podem estar em qualquer outro local e eles precisam ter um mínimo de capacidade de saber identificar esses problemas e se relacionar com as pessoas de forma que possam ajudar". (D3).

Os docentes complementam que as possibilidades de re-significação do fenômeno da loucura devem ter por base um conhecimento adquirido através de um saber elaborado, cientificamente eficaz e consistente. Nas falas evidenciamos uma preocupação dos docentes em mostrar que o portador de transtorno psíquico é um ser como os outros e que a doença mental é uma expressão do sofrimento humano. Fica também claro uma preocupação de que o aluno absorva essa concepção; seja capaz de expressar suas dificuldades no manejo do paciente; consiga aproximar-se do paciente; identifique os problemas de Saúde Mental e saiba se relacionar terapeuticamente com o outro para ajudar a pessoa em sofrimento.

Toda proposta de atendimento deve ser embasada em referenciais teórico-metodológicos que subsidiem esse cuidado humanizado. As diferentes abordagens teóricas (como a psicanálise, a saúde coletiva, o relacionamento interpessoal) e os diferentes espaços de aulas práticas - serviços de saúde mental - segundo alguns docentes contribuem para o resgate do valor do outro, além de valiosos instrumentos de ensino e de aprendizagem. As seguintes falas nos mostram essa tendência:

"Se você trabalha numa clínica, por exemplo, com referencial teórico da psicanálise, eu acho que, ao poder olhar pra cada um como alguém que vai ter uma caminhada na vida... Isso te permite humanizar o atendimento, fazer um atendimento que considere mais o ser humano. Acho que isso faz com que o aluno também se sinta mais responsável pelo tipo de inserção que ele tem no serviço. Então quando ele vai fazer qualquer tipo de cuidado junto com o paciente ele sabe que, dependendo do manejo que ele tem isso pode favorecer esse cara a se tornar mais dependente da equipe ou independente. Então acho que isso já faz o aluno assumir outro lugar nesse processo de ensino (...) $A$ gente acreditava que era o hospício que tornava as pessoas deshumanizadas e em técnicas capazes de resgatar a humanidade dessas pessoas. Uma, era o grupo, as pessoas podiam se humanizar umas com as 
outras e ficar menos sozinhas na sua experiência de adoecimento." (D1).

"O que tem na comunidade que pode ser subsídio para este paciente? Eu acho que minha última experiência foi mais rica nesse sentido porque a gente pode ver o quanto a enfermagem psiquiátrica precisa se aproximar da enfermagem de saúde pública, de saúde coletiva e procurar outros recursos para o paciente. Eu estudei, por exemplo, qualidade de vida no meu mestrado, eu tinha uma visão bem assim de que o paciente precisava me falar da qualidade de vida dele. Depois fazendo este trabalho, eu tenho visto e acompanhado alguns autores que trabalham com essa questão da qualidade de vida e chegado à conclusão de que tanto melhor é qualidade de vida do sujeito quanto mais ele tem recursos na comunidade que possa ajudá-lo" (D3).

\section{DISCUSSÃO}

Nossa sociedade convive diariamente com a classificação de tudo que nos é apresentado. Com relação à saúde, há uma polarização entre o que seria normal e o que seria patológico. Isso se deve ao fato da incorporação do saber médico nas práticas em saúde, advindas com o modelo econômico capitalista (SILVA JÚNIOR, 1998).

Com relação ao fenômeno da loucura, entendemos que as representações socialmente construídas nos acentuam as discrepâncias entre o que seria normal ou patológico, transformando-se em uma polarização que nos parece difícil de ser trabalhada e redimensionada, mesmo em tempos de reforma psiquiátrica. As concepções sobre loucura que permeiam o nosso cotidiano foram tão incorporadas pelo imaginário social que hoje distinguir o normal do patológico se tornou uma prática cultural.

Desde o final do século XVIII, quando a loucura passa a ser reconhecida como doença e então institucionalizada no manicômio, a separação do louco do convívio social é defendida. Através do tratamento moral instituído por Pinel, o louco se vê obrigado a seguir condutas e rotinas impostas pelo hospital, ocorrendo uma perda de identidade pessoal que leva à mortificação do "eu", responsável por gerar graves tensões psicológicas e zonas de conflito na instituição (CASTEL, 1978; FOUCAULT, 1993; GOFFMAN, 1999; SHORTER, 2001).

O que parecia uma alternativa terapêutica para o quadro de loucura, aos poucos começa a ser discutido, principalmente por intelectuais e movimentos sociais. Após a segunda guerra mundial, as experiências psiquiátricas que emergem de uma nova visão com base nos direitos humanos permitiram refletir acerca das determinações e implicações sociais da exclusão do louco do convívio social e familiar. Os movimentos reformistas apontam para a re-significação do louco, a conseqüente destituição do tratamento moral de Pinel e a reforma do modelo asilar, com a construção de espaços sociais ampliados, em que a família, a comunidade e o próprio indivíduo considerado doente pudessem conviver juntos e participar do plano/projeto terapêutico (PESSOTTI, 1994).

A assistência humanizada ao portador de sofrimento psíquico ${ }^{4}$ pressupõe um olhar para a história da loucura, sendo uma prática e um saber concebidos e arquitetados coletivamente, ou seja, uma junção de atitudes, papéis, culturas e imaginários sociais. Não há sobre ela um consenso, uma verdade absoluta, sendo uma sucessão de discursos complementares e contraditórios que irrompem e reconstroem-se ao longo da evolução da humanidade. Mesmo assim, esses diferentes olhares, aos poucos, têm contribuído para o entendimento do indivíduo considerado louco e da loucura como um momento de sua existência (MIRANDA, 1994).

As falas dos docentes entrevistados demonstram a preocupação da disciplina de enfermagem psiquiátrica e saúde mental com a humanização do atendimento em saúde mental. As relações interpessoais estabelecidas entre alunos e pacientes, diminuindo os medos, as inseguranças e a rotulagem social do considerado "diferente", tão presentes no senso comum, podem contribuir para a re-significação do louco e do fenômeno da loucura nos nossos espaços sociais de ensino e de assistência.

Reconhecemos que conteúdos incorporados nas aulas teóricas e práticas ancoradas no referencial da psicanálise, do relacionamento interpessoal e da saúde coletiva com o objetivo de humanizar o atendimento em saúde mental, segundo estes docentes, colaboram para 0 redimensionamento do valor do indivíduo que padece psiquicamente.

Humanizar o atendimento é valorizar o significado atribuído pelo ser humano à sua experiência de adoecimento, ao seu sofrimento, reconhecendo as relações interpessoais como um processo, que permeia a organização produtiva do trabalho e suas dimensões técnico-assistenciais. Resgatar o espaço do acolhimento, da escuta atenta e interessada nas necessidades e expectativas das pessoas pode ser um estímulo à transformação das práticas em saúde, em que a clínica não é ignorada, mas associada ao conhecimento de mundo daqueles que procuram diariamente um serviço de saúde (BAREMBLITT, s/d).

\footnotetext{
${ }^{4}$ Termo adotado após a III Conferência Nacional de Saúde Mental, realizada em 2001, para substituir a denominação de "doença mental", usada pelo saber médico desde o século XIX que nos remete à rotulagem, à inexpressão do ser humano e à sua exclusão social como forma de tratamento e reabilitação. O termo "sofrimento psíquico" vem a substituir a "doença mental", designando aquele que está experienciando uma situação de sofrimento.
} 
Em saúde mental, a humanização do atendimento vem sendo uma estratégia proposta pela reforma psiquiátrica, como um compromisso ético dos profissionais de saúde. Acreditamos que o processo de se re-situar o sujeito que sofre dentro dessa perspectiva humanizada seja um desafio permanente para docentes e profissionais da área de saúde mental. Dentro desse olhar, o docente tem um papel fundamental na (des)construção de conceitos e definições clássicas sobre a loucura, no repensar das atividades acadêmico-profissionais dos futuros enfermeiros, estando essa atividade estreitamente vinculada à sua experiência profissional. Os docentes entrevistados ressaltam a importância de sensibilizar o educando, problematizando as suas concepções, contribuindo assim para se repensar a realidade assistencial.

Uma ação humana somente existe quando existe uma realidade objetiva, ou seja, um mundo próprio em que se mesclam contradições, discursos, práticas e limites pessoais. Cabe ao homem desafiá-los, (des)construindo para depois construir, pois sem isso não haveria ação humana. A verdadeira educação dá-se no sentido da emergência do interior para o exterior, quando o educando pode ir mais além de si mesmo, captando a realidade, discutindo-a, conhecendo-a, para depois transformá-la:

"A educação que se impõe aos que verdadeiramente se comprometem com a libertação não pode fundar-se numa compreensão dos homens como seres 'vazios' a quem o mundo 'encha' de conteúdos; não pode basear-se numa consciência espacializada, mecanicistamente compartimentada, mas nos homens como 'corpos conscientes' e na consciência como consciência intencionada ao mundo. Não pode ser a do depósito de conteúdos, mas a da problematização dos homens em suas relações com o mundo" (FREIRE, 1987, p.67).

Entendemos que, no processo de ensinoaprendizagem, o educando deve ser estimulado a pensar sobre as alternativas de assistência, fazendo parte das discussões e do resgate das diferentes concepções. A humanização do atendimento inicia-se nos espaços acadêmicos, num processo de açãoreflexão-ação. É importante estimular que o aluno tenha em mente as suas possibilidades, necessidades, particularidades, e que o docente continue inserindo-o como sujeito participante desse contexto.

Toda e qualquer ação em saúde que valorize o sujeito como um co-partícipe do atendimento está retomando a importância dele no processo de saúdedoença. Resgatando no conceito de integralidade do cuidado, sua potencialidade de combater uma visão mecanicista e biologizante dos serviços de saúde em busca de uma melhora da qualidade de vida dessa pessoa (MERHY, 1997).

Pelo que pudemos notar também, parte dos depoimentos analisados nos traz algumas contribuições da psicanálise como referencial teóricometodológico para o entendimento dos comportamentos humanos. No início do século XX, as experiências psicoterapêuticas de Freud, foram aos poucos sendo incorporadas às práticas clínicopsiquiátricas, através dos avanços nos estudos de áreas paralelas tais como o serviço social e a psicologia. Com a Terapia Centrada no Cliente de Carl Rogers se consolida uma psicologia de orientação humanista, em que a reconstrução do self substituía o manejo psiquiátrico. O relacionamento terapêutico como seu instrumento parte dum aconselhamento psicológico facilitador, orientado à auto-interpretação e à reflexão intrapessoal, possibilitando ao indivíduo a reconstrução do autoconceito, de suas atitudes e de sua valorização (SHORTER, 2001).

Nos anos 50 o referencial teórico da psicanálise despontava como possibilidade teóricometodológica em algumas escolas de enfermagem, transformando o olhar centrado na psicopatologia e ampliando os espaços de aprendizado no enfoque psicodinâmico. Essa prática se configurou como uma das primeiras modificações do ensino teórico de enfermagem psiquiátrica, iniciando o aprimoramento do cuidado com base na valorização da expressão do paciente e no relacionamento estabelecido entre ele e o enfermeiro (KIRSCHBAUM, 1994).

Peplau foi uma enfermeira que já na década de 50 adotou técnicas psicodinâmicas no tratamento destinado aos pacientes. Com sucesso, ela desenvolveu novas estratégias de cuidado centradas na escuta e na interpretação do comportamento humano. $\mathrm{Na}$ década de 60, Travelbee deu continuidade aos estudos de Peplau e associou as técnicas psicoterápicas ao cuidado de enfermagem psiquiátrica, valorizando o relacionamento interpessoal terapêutico como parte do tratamento que visava a resgatar a realidade objetiva do paciente. Isso era fundamental para a relação deste com o mundo externo, sendo o referencial-modelo adotado na maioria das escolas de enfermagem e referência para estudos posteriores (ROCHA, 1994; CAMPOS \& BARROS, 2000; KANTORSKI, 2002).

O fenômeno de interação com o outro, numa relação interpessoal, não pode ser conduzido verticalmente, mas deve fluir através do contato das pessoas participantes que podem reconhecer-se juntas, crescer juntas com a experiência, repensando fatos, ações e atitudes (BUBER, 1974; TRAVELBEE, 1979; PEPLAU, 1990).

O ensino de relacionamento terapêutico e comunicação terapêutica não são somente enfatizados nas disciplinas de saúde mental e enfermagem psiquiátrica, mas também em outras disciplinas de formação do enfermeiro. Ministrar 
conteúdos sobre relacionamento terapêutico e comunicação terapêutica permite o resgate da enfermagem enquanto profissão que lida principalmente com o sofrimento humano e não somente com a doença (KANTORSKI et al, 2005).

A influência do movimento de reforma psiquiátrica brasileira e do referencial da reabilitação psicossocial permite uma revisão de conceitos e uma incorporação destes na formação do enfermeiro a partir do início da década de 90 . O conteúdo da reabilitação psicossocial resgata as intervenções terapêuticas que consideram o contexto de vida do portador de sofrimento psíquico, suas possibilidades e demandas, visando estimular à auto-estima, as atividades cotidianas, a minimização das limitações e a potencialização dos aspectos saudáveis que Ihe permitem sua reconstrução pessoal e social (KANTORSKI e SCATENA, 2002).

Ao que nos parece, a abordagem humanizada com que estes docentes vêm trabalhando têm-se tornado um caminho de superação das concepções do senso comum de exclusão e segregação da loucura. O aluno que entra em contato com a loucura em suas diferentes manifestações também passa a compreender que o louco sofre, tem suas necessidades de carinho, amor, possui expectativas e limitações, independente do comportamento que apresente e de suas atitudes. Mesmo que em nosso imaginário cultural esse olhar rotulante ainda esteja muito presente e seja difícil de ser transformado, compreendemos que as aulas práticas em serviços substitutivos ao modelo do manicômio propiciam a mudança desse senso comum que carrega concepções excludentes do louco e das manifestações da loucura.

\section{CONCLUSÕES}

O estudo nos mostrou algumas das expectativas dos docentes com relação ao ensino do cuidado em saúde mental. Os docentes enfatizam a humanização do cuidado como sendo um fator preponderante da qualidade do atendimento prestado pelos profissionais de saúde com vistas à superação das concepções do senso comum sobre loucura e suas representações.

As expectativas dos docentes entrevistados nos permitem refletir sobre saberes e práticas pautados num paradigma de humanização e inserido em um contexto de reforma das práticas psiquiátricas.

Vivenciamos uma realidade ainda influenciada por concepções clássicas sobre a loucura, que são problematizadas no contexto de ensino-aprendizagem partilhado pelos docentes entrevistados e seus alunos cotidianamente nos serviços de saúde mental em que ocorrem aulas práticas de enfermagem psiquiátrica e saúde mental.

\section{REFERÊNCIAS BIBLIOGRÀFICAS}

ARRUDA, M. Humanizar o Infra-humano - A Formação do Ser Humano Integral: Homo evolutivo, práxis e economia solidária. Petrópolis: Vozes; 2003. BAREMBLITT, G. Que se entende por humanidade e humanização? Belo Horizonte: Instituto Felix Guattari - Fundação Gregório F. Baremblitt; s.d.

BUBER, M. Eu e Tu. São Paulo: Perspectiva; 1974.

CAMPOS, C.M.S; BARROS, S. Reflexões sobre o processo de cuidar da enfermagem em saúde mental. Revista da Escola de Enfermagem da USP, v.34, n.3, p.271-6, 2000.

CASTEL, R. A ordem psiquiátrica: a idade de ouro do alienismo. Rio de Janeiro: Graal; 1978.

FOUCAULT, M. História da loucura na Idade Clássica. 3 ed, São Paulo: Perspectiva; 1993.

FREIRE, P. Pedagogia do oprimido. 17 ed, Rio de Janeiro: Paz e Terra; 1987.

GOFFMAN, E. Manicômios, prisões e conventos. 6 ed, São Paulo: Perspectiva; 1999.

KANTORSKI, L.P. Mental health care in Brazil. Journal of Psychiatric and Mental Health Nursing, v.9, n.3, p.251-3, 2002.

KANTORSKI, L.P. et al. Relacionamento terapêutico e ensino de enfermagem psiquiátrica e saúde mental: tendências no Estado de São Paulo. Revista da Escola de Enfermagem da USP, v.39, n.3, p.317-24, 2005.

KANTORSKI, L.P, SCATENA, M.C.M. Reabilitação psicossocial - abordagem no ensino de enfermagem. Revista de Enfermagem da UERJ, v.10, n.3, p.222-4, 2002.

KIRSCHBAUM, D.I.R. Análise Histórica das Práticas de Saúde no Campo da Assistência Psiquiátrica no Brasil, no Período Compreendido entre as Décadas de 20 e 50. 1994. Tese (Doutorado em Ciências Médicas) Campinas: Faculdade de Ciências Médicas, Universidade de Campinas.

MERHY, E.E. Em busca da qualidade dos serviços de saúde: os serviços de porta aberta para a saúde e o modelo tecnoassistencial em defesa da vida (ou como aproveitar os ruídos do cotidiano dos serviços de saúde e colegiadamente reorganizar o processo de trabalho na busca da qualidade das ações de saúde). In: CECÍLIO, L.C.O (Org). Reinventando a mudança na saúde. Saúde em Debate - Série Didática; 1997.

MINAYO, M.C.S. O desafio do conhecimento: pesquisa qualitativa em saúde. São Paulo/Rio de Janeiro: Hucitec/Abrasco; 1998.

MIRANDA, C.M.L. O parentesco imaginário: história e representação social da loucura nas relações do espaço asilar. São Paulo: Cortez, Rio de Janeiro: Editora da UFRJ; 1994.

PEPLAU, H.E. Relaciones interpersonales en enfermería. Barcelona: Salvat Editores S.A; 1990.

PESSOTTI, I. A loucura e as épocas. 2 ed, Rio de Janeiro: Ed. 34; 1994.

ROCHA, R.M. Enfermagem psiquiátrica: que papel é este? Rio de Janeiro: Te Cora; 1994. 
SILVA JÚNIOR, A.G. Modelos tecnoassistenciais em saúde: o debate no campo da saúde coletiva. São Paulo: Hucitec; 1998.

SHORTER, E. Uma história da psiquiatria: da era do manicômio à idade do prozac. Lisboa: Climepsi Editores; 2001.

SOUZA, MCB; ALENCASTRE, M.B. Produção de Enfermagem Psiquiátrica no Brasil: 1932-1993. Revista Brasileira de Enfermagem, v.52, n.2, p.27182, 1999.

TRAVELBEE, J. Intervención en enfermería psiquiátrica. Colombia: Carvajal; 1979.

Artigo recebido em 13.11.2006

Aprovado para publicação em 29.12.2006 